\title{
Assessment of the dust sources over Central and Southwest Asia with emphasis on the Sistan dust storms
}

\author{
Alireza Rashki $^{1, *}$, and Dimitris Kaskaoutis ${ }^{2}$ \\ ${ }^{1}$ Department of Desert and Arid Zones Management, Ferdowsi University of Mashhad, Mashhad, Iran \\ ${ }^{2}$ Institute for Environmental Research and Sustainable Development, National Observatory of Athens, 11810 Athens, Greece
}

\begin{abstract}
Central and Southwest (SW) Asia are usually suffered by dust events of various intensity due to extended arid/desert regions and, therefore, the statistical evaluation of the dust activity and sources over the region has received an increasing interest. This study analyses the characteristics of the dust events and their sources over the Central and Southwest Asia from 2002 to 2018, based on meteorological observations at stations in Turkmenistan, Uzbekistan, Iran, Afghanistan and Pakistan, combined with Aerosol Optical Depth (AOD) at $10 \mathrm{~km} \times 10 \mathrm{~km}$ derived from MODIS and a new 1-km high resolution algorithm. The dust events are classified based on visibility recordings and WMO codes, as dusty days (vis $<10 \mathrm{~km}$ ) and dust storms for visibility below $1 \mathrm{~km}$. In general, the highest frequency of the dust storms is observed in the Sistan Basin, Iran and around the deserts of southern Afghanistan, while the dust-plume pathways have a distinct north-to-south pattern, from Central Asia to SW Asia and the Arabian Sea. Trend analysis in the Deep Blue MODIS AOD retrievals shows positive AOD trends over large parts of the Central Asia and negative over the Southwest Asia and Sistan. High resolution (1-km) AODs indicated that some parts of the Hamoun ephemeral lakes and the eastern part of the Sistan basin are the most active hotspot areas for dust emissions.
\end{abstract}

\section{Introduction}

The Central and Southwest (SW) Asian region has a continental-dry climate due to its far distance from the sea and the mountainous ranges that prevent the arrival of humid air masses and release of precipitation. During summer, the hot and extreme dry conditions lead to high evaporation rates and limitation of vegetation only at the foothills of specific mountains close to the Caspian Sea and along the Amu Darya valley in Turkmenistan. High mountains along with deep valleys, depressions and lowlands form a rough topography that controls the local/regional meteorology and the formation of thermal low-pressure systems and advection of dust [1]. Previous studies $[2,3]$ have shown that the $\sim 65 \%$ of the dry lands in SW and Central Asia have high potential to become active dust sources, mostly located in topographic-low areas such as the Karakum desert in Turkmenistan, Margo and Registan deserts in Afghanistan, the Dasht-eLut and Dasht-e-Kavir deserts in Iran and the sandy valleys within the Makran mountains along the north coast of the Arabian Sea. In addition, some other regions, which also serve as important dust sources have become susceptible to wind erosion and dust emissions through human disturbances and land use - land cover changes, as the desiccation of the Aral Sea [4, 5], the ephemeral Hamoun lakes in Sistan [6] and the dryness of the Jazmurian lake [7]. The arid climate along with the rough topography, the vegetation scarcity and the extended sandy and clay areas are important factors that control the dust activity over Central Asia [8].

The main objectives of the present study are to examine the statistical evaluation of the dust activity over the SW Asia, to analyse the spatio-temporal evolution and trends in MODIS Aerosol Optical Depths (AODs), and to detect the Sistan dust storms and emission sources using high resolution (1-km) MODIS products through a new algorithm for remote sensing of the dust sources.

\section{Data set and analysis}

The geographic map of the study area superimposed by the dust-storm days after analysing the meteorological data at the selected stations is shown in Fig. 1. In this study, meteorological stations spread across Central and SW Asia (see Fig. 1) were selected based on as long and complete as possible data series for years after 2010. The meteorological parameters used here are the horizontal visibility (in $\mathrm{km}$ ), wind speed (in $\mathrm{ms}^{-1}$ ) and the WMO METAR codes. These datasets were obtained from the archives of automated airport weather observations (AWOS) network of the Iowa Environmental Mesonet

\footnotetext{
Corresponding author: a.rashki@um.ac.ir
} 
(IEM) (http://mesonet.agron.iastate.edu). In this study, WMO METAR codes (e.g. DS, SA, DU) and visibility records were used to determine the dust days (DD) and dust storms days (DSD) for each station. Based on the visibility records, the dust events can be classified in several groups, from which the most commonly used are (i) dust in suspension with visibility around $10 \mathrm{~km}$, (ii) blowing dust when the visibility is below $10 \mathrm{~km}$; iii) dust storms (visibility below $1 \mathrm{~km}$ ) and (iv) severe dust storms with visibility below $200 \mathrm{~m}$ [9, 10]. Initially, the classification was performed on the hourly data series and then, the dusty hours were grouped according to their intensity forming the data series of dust-insuspension hours (DiSH), blowing-dust hours (BDH) and dust-storm hours (DSH). As "dust day" we consider a day with at least one hour with visibility below $10 \mathrm{~km}$ regardless of intensity. In the next step, this day was characterized as dust-storm day (DSD) or blowing-dust day (BDD) if at least one hour corresponds to dust-storm or blowing-dust event, respectively; otherwise, it is classified as dust-in-suspension day (DiSD). For assessing the annual average of the dusty days, we divided the total number of dusty days per the total years. Finally, for statistical evaluation of the results (i.e., trends, comparison between data groups), the t-test at $95 \%$ confidence level was used.

\section{CasHKI (Caspian Sea-Hindu Kush Index)}

Another objective of the present study is to relate the statistical evaluation of the dust activity over the SW Asia to changes in Caspian Sea-Hindu Kush Index (CasHKI). CasHKI is defined as CasHKI = MSLPanom.CS - MSLPanom.HK, where MSLP ${ }_{\text {anom. }}$ is the anomaly from the climatology for the mean sea level pressure between specific domains over the Caspian Sea (CS) and Hindu Kush (HK). The MSLP anomalies were obtained via NCEP/NCAR re-analysis. CasHKI has been identified as regulatory factor for changes in dust activity over SW Asia, in general, and in Sistan, in more particular and was found to strongly affect the Levar wind $[11,12]$. So, changes in the MSLP pattern, especially over the Caspian Sea are very important for the activation of the dust sources in the downwind regions due to effects in the wind regime.

\section{Deep blue AOD at $10 \mathrm{~km}$}

The 17-year (2002-2018) averaged AODs from Deep Blue Terra MODIS retrievals over the study region (Fig. 1), show large values of the highly polluted Indus Basin due to combined effects of anthropogenic aerosol and dust [13], as well as over specific desert areas rendering them as hot-spot dust sources. These areas are the Sistan basin, the Jazmurian dried lake, parts in the western Karakum desert and in the south of the Aral Sea, the coastal Makran mountains and sources in the easternmost Arabian Peninsula. Over these areas, the mean AOD reaches at very high values, usually above 1.5 , rendering them as highly turbid environments.

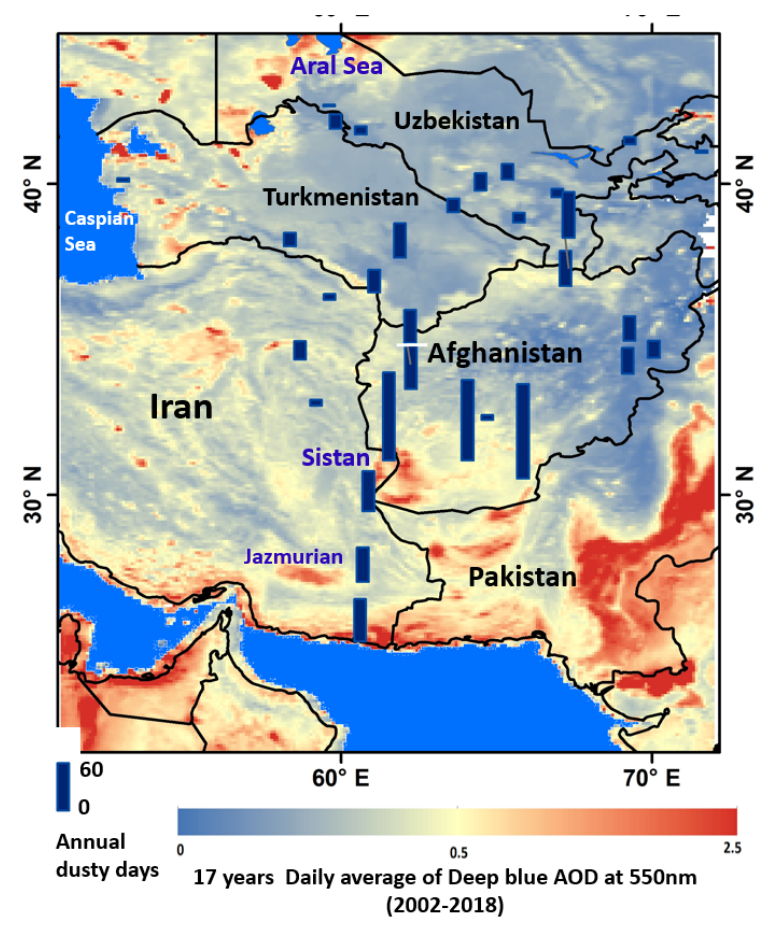

Figure 1. Spatial distribution of the mean MODIS-AOD550 during the period 2002-2018 over SW Asia, superimposed by bars corresponding to the number of the annual dusty days at selected stations during the period 2002-2018.

\section{Long-term trend of AOD}

Detection of trends in dust aerosols has become of great importance to better understand the action of atmospheric and the rapid evolution of the Earth's climate over the desert areas [14]. In this context, Deep Blue MODIS AOD was used to study the trends over the Central and SW Asia between 2002 and 2018, where dust-aerosol emissions are frequent and on certain cases very intense. Our analysis corroborates a previously identified positive AOD trend over large parts of the Central Asia and negative over the most parts of the SW Asia (Fig. 2). More specifically, positive AOD trends are detected over the playas west of the Caspian Sea and in the southern parts of the Aral Sea, verifying previous observations [5] of intensification of the dust emissions in these areas due to shrinking of the water levels in the Aral Sea and extended desertification. Positive AOD trends in the order of $2 \%$ to $10 \%$ are also seen in the southern Karakum desert, whereas over Sistan and in the south Afghanistan deserts a negative trend is observed. This indicates a declining trend in dust activity during the last years, and especially after the extreme dusty period during the beginning of the 2000s attributed to extreme droughts (1999-2003) over Sistan [6]. 


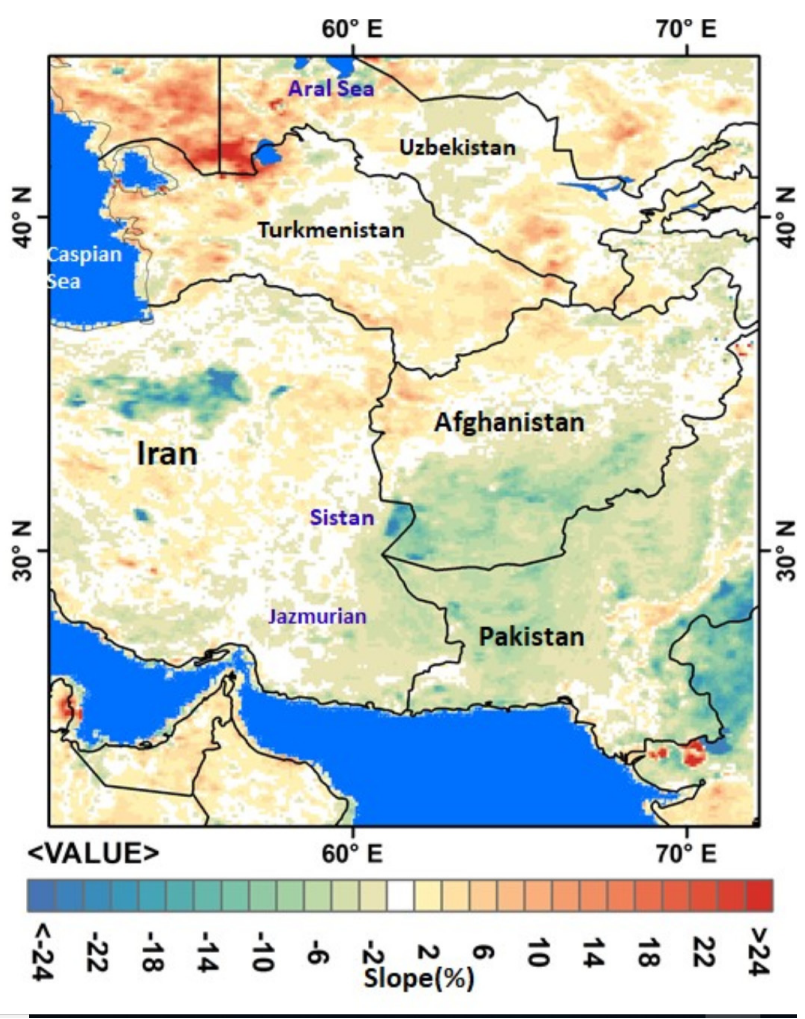

Figure 2. Spatial distribution of the slope values (\%) obtained from the linear regression of the AOD trends during 2002-2018.

\section{High resolution dust algorithm to detect hot spot sources of dust}

To detect dust-emission sources in high-resolution, the ISMI Index was used, which is an integration of the Sara $[15,16]$ and BADI [17] algorithms. The Sara algorithm for high brightness areas has lower accuracy and indicates higher values, while BADI shows lower values in the source regions. Combining these two models with the use of reflectance over the accumulation period of the queue (4-16 days) of MODIS product (MOD43A1) provides better results. ISMI algorithm uses a new model that has been run for dust-storm events over the Central and SW Asia during summer 2018, and the accuracy of the derived AODs has been validated with AOD data measured with a Handheld Sun Photometer (Calitoo $\left.{ }^{\circledR}\right)$ at the ground. The implementation of this index over Sistan for dust storms occurred during 2002-2018 reveals the dust emission sources in the Hamoun-lake complex and the intense dust plumes with a high resolution of $1 \mathrm{~km}$ (Fig. 3 for a case of 23 August 2018). The results identify the Hamoun lake and eastern part of the Sistan basin as main sources of massive dust emissions. The very high resolution allows for identification of specific small areas in the Hamoun lakes, which are responsible for the highest dust emissions. In addition, the pathway of the dust emissions can be clearly identified. This is a case study, while the ISMI index was applied to several dust events covering a long-term period in order to examine a climatology of the Sistan emissions and a high-resolution identification of the dust sources. This would help policy makers and local authorities on planning strategies for mitigation of the dust impacts.

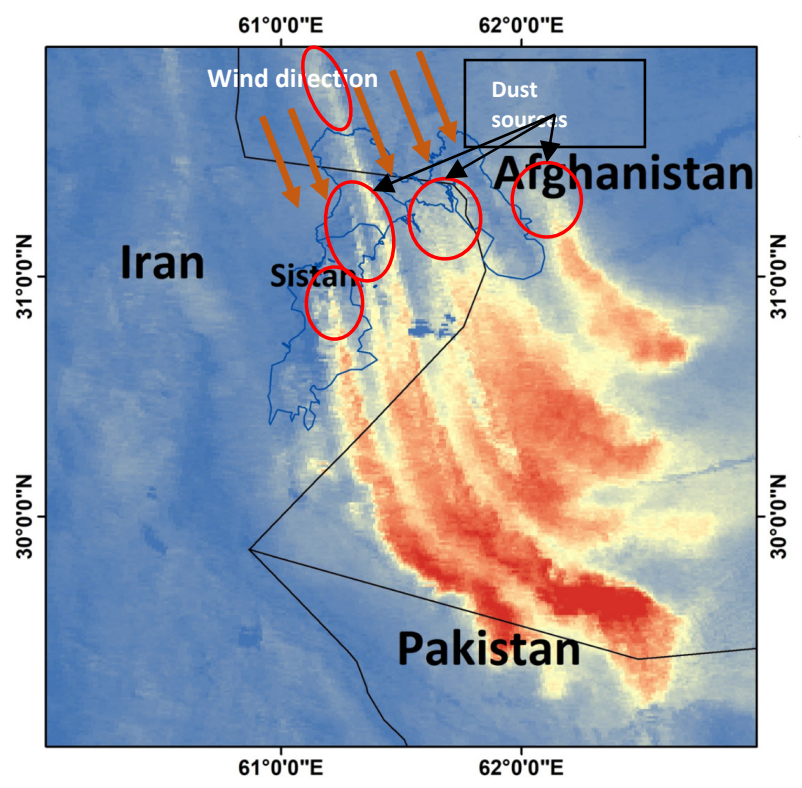

Figure 3. Spatial distribution of 1-km AOD from MODIS over the Sistan Basin on 23 August 2018 The high AOD values show the emission and movement of an intense dust storm.

\section{Conclusions}

In this study, we examine the evolution in dust activity over the Central and SW Asia based on meteorological data of visibility at several stations over the region. The results showed that the most frequent and intense dust storms originate from the Sistan basin in southeast Iran and deserts in south Afghanistan. The long-term trend (2002-2018) in MODIS-derived Deep Blue AOD showed increase in dust activity over the playas around the west of the Caspian Sea and in southern flanks of the Aral Sea due to desertification, while a decline in dust activity was found over Sistan. The application of a new ISMI index for detection of the dust sources and dustplume routes with very high resolution $(1 \mathrm{~km})$ over Sistan enables to identify the dust sources in the Hamoun-lakes complex with high accuracy and was applied for the first time over Sistan.

\section{References}

1. D.G. Kaskaoutis, A. Rashki, E.E. Houssos, A. Mofidi, D. Goto, A. Bartzokas, P. Francois, M. Legrand, Clim. Dyn. 45(1-2), 407-424 (2015)

2. J.F. Léon, M. Legrand. Geophys. Res. Lett. 30(6), 1309 (2003)

3. P. Micklin, Earth Planet. Sci. 35(1), 47-72 (2007)

4. P. Ginoux, J.M. Prospero, T.E. Gill, N.C. Hsu, M. Zhao, Rev. Geophys. 50, RG3005 (2012)

5. Y. Ge, J. Abuduwaili, L. Ma, D. Liu, Water Air Soil Pollut. 227(2), 1-12 (2016) 
6. A. Rashki, D.G. Kaskaoutis, A.S. Goudie, R.A. Kahn, Sci. Total Environ. 463-464, 552-564 (2013)

7. A. Rashki, M. Arjmand, D.G. Kaskaoutis, Aeolian Res. 24, 145-160 (2017)

8. N.S. Orlovsky, L. Orlovsky, R. Indoitu, Arid Ecosyst. 3(4), 227-234 (2013)

9. M. Rezazadeh, P. Irannejad, Y. Shao, Aeolian Res. 10, 103-109 (2013)

10. A. Rashki, D.G. Kaskaoutis, A. Sepehr, Catena 165, 590-603 (2018)

11. D.G. Kaskaoutis, E.E. Houssos, A. Rashki, P. Francois, M. Legrand, D. Goto, A. Bartzokas, H.D. Kambezidis, T. Takemura, Glob. Planet. Change 137, 10-23 (2016)

12. D.G. Kaskaoutis, E.E. Houssos, F. Minvielle, A. Rashki, I. Chiapello, U.C. Dumka, M. Legrand, Glob. Planet. Change 169, 16-33 (2018)

13. K. Alam, S. Qureshi, T. Blaschke, Atmos. Environ. 45(27), 4641-4651 (2011)

14. A. Chedin, V. Capelle, A. Noelle, N.A. Scott, Atmos. Res. 212, 120-129 (2018).

15. M. Bilal, J.E. Nichol, M.P. Bleiweiss, D. Dubois, Remote Sens. Environ. 136, 135-145 (2013)

16. M. Bilal, J.E. Nichol, P.W. Chan, Remote Sens. Environ. 153, 50-60 (2014)

17. H. Yue, C. He, Y. Zhao, Q. Ma, Q. Zhang, Int. J. Appl. Earth Obs. 57, 166-176 (2017) 